\title{
Prevention and care of hepatitis B in the rural region of Fatick in Senegal: a healthcare workers' perspective using a mixed methods approach
}

Tchadine Djaogol ${ }^{1}$, Marion Coste ${ }^{1,2}$, Fabienne Marcellin $^{1,2}$, Antoine Jaquet ${ }^{3}$, Fanny Chabrol ${ }^{4}$, Tamara Giles-Vernick ${ }^{5}$, Aldiouma Diallo ${ }^{6}$, Maria Patrizia Carrieri ${ }^{1,2^{*}}$ (D), Sylvie Boyer ${ }^{1}$ and for the ANRS 12356 AmBASS Study Group

\begin{abstract}
Background: In countries where hepatitis B virus (HBV) is endemic, including Senegal, the World Health Organization recommends systematic HBV screening of pregnant women and vaccination at birth to prevent mother-to-child transmission (MTCT). This study investigated healthcare workers' (HCW) knowledge and practices regarding HBV prevention and care in the rural region of Fatick in Senegal, as well as challenges they faced in implementing prevention activities related to HBV MTCT.

Methods: A mixed-methods survey was conducted between May-July 2017 among 112 HCW working in 15 healthcare facilities in two districts of the Fatick region using face-to-face questionnaires and semi-structured interviews. Descriptive statistics and chi-square/Mann-Whitney tests were used to analyze quantitative data, while qualitative data were analyzed thematically.

Results: The study population included $87 \mathrm{HCW}$ in the quantitative component (83\% women, median age [interquartile range, IQR] = 35 [31-40] years) and 11 in the qualitative component. A knowledge gap was observed in key areas of HBV infection: only 24, 51 and 38\%, respectively, correctly reported that early HBV acquisition is associated with a high risk of developing chronic infection, that perinatal transmission is one of the main modes of HBV transmission in Senegal, and that three to four doses of HBV vaccine are required to ensure immunization in children. Despite good acceptability of systematic screening of pregnant women and vaccination at birth, only $48 \%$ of HCW mainly involved in prenatal care and $71 \%$ of those involved exclusively in vaccination routinely performed these two key interventions. HCW reported several structural barriers that may hinder their implementation: a lack of training in HBV and in counseling, poor availability of rapid diagnostic tests (RDT), high costs of both screening and treatment, a lack of adequate information on treatment options and missed opportunities for vaccination at birth.

\footnotetext{
* Correspondence: pmcarrieri@aol.com

${ }^{1}$ Aix Marseille Univ, INSERM, IRD, SESSTIM, Sciences Economiques \& Sociales

de la Santé \& Traitement de I'Information Médicale, Marseille, France

${ }^{2}$ ORS PACA, Observatoire régional de la santé Provence-Alpes-Côte d'Azur,

Marseille, France

Full list of author information is available at the end of the article
}

(c) The Author(s). 2019 Open Access This article is distributed under the terms of the Creative Commons Attribution 4.0 International License (http://creativecommons.org/licenses/by/4.0/), which permits unrestricted use, distribution, and reproduction in any medium, provided you give appropriate credit to the original author(s) and the source, provide a link to the Creative Commons license, and indicate if changes were made. The Creative Commons Public Domain Dedication waiver (http://creativecommons.org/publicdomain/zero/1.0/) applies to the data made available in this article, unless otherwise stated. 
(Continued from previous page)

Conclusions: HCW working in the Fatick region may be insufficiently trained and supported to effectively implement HBV prevention strategies. Our findings suggest an urgent need to strengthen MTCT prevention in this region, by improving HCW knowledge in key areas of HBV infection, providing RDT and antiviral treatment at low cost, and enhancing community-based interventions for the timely vaccination of newborns.

Keywords: Hepatitis B, HBV, Mixed-methods, Healthcare workers, Prevention, Vaccination at birth, Senegal, Africa, Vertical transmission, Mother-to-child transmission, Decentralized care

\section{Background}

Among the 257 million people chronically infected by hepatitis $\mathrm{B}$ virus $(\mathrm{HBV})$ worldwide, 60 million are living in sub-Saharan Africa, the second most affected region in the world after Asia [1, 2]. HBV prevalence is especially high in West Africa with rates estimated between 7 and $18 \%$ in the adult population, depending on the country [3].

HVB prevention, and especially prevention of mother-tochild transmission (MTCT), is a high priority in this endemic region for three main reasons. First, perinatal (vertical) transmission and early childhood (horizontal) transmission are the main modes of HBV acquisition in this area $[2,4,5]$. Second, approximately $90 \%$ of children infected during their first year of life will develop chronic HBV infection (versus only $5 \%$ of people infected during adulthood). Third, compared with horizontal transmission and infection acquired during adulthood, vertical transmission is associated with a higher risk of serious liver complications later on in life including cirrhosis and hepatocellular carcinoma $[2,6,7]$.

The World Health Organization (WHO) recommends the following three key interventions in all endemic areas: i) systematic screening of pregnant women, ii) vaccination of newborns within $24 \mathrm{~h}$ with $\mathrm{HBV}$ monovalent vaccine, followed by 2 to 3 additional vaccine doses, and iii) treatment of $\mathrm{HBV}$-positive pregnant women using antiviral therapy based on tenofovir [2, 8, 9].

In Senegal, the prevalence of chronic HBV infection is estimated at $11 \%$ according to a recent systematic review [3]. HBV screening is not mandatory for pregnant women but is generally proposed during prenatal consultations. In addition to the pentavalent vaccine administrated to newborns at 6,10 and 14 weeks after birth, in 2016 vaccination at birth (first dose) was introduced as part of the country's expanded immunization program (EPI) [10]. A working group was also initiated in 2016 to develop national guidelines to promote access to HBV treatment - including access for pregnant women - at the decentralized level of the healthcare system. At the time of this study, however, these guidelines were not yet officially adopted, and access to antiviral treatment was only available in major hospitals located in the country's two main cities, Dakar and St Louis.

Good adhesion to WHO recommendations and adequate training of healthcare workers $(\mathrm{HCW})$ are essential to ensure successful prevention of HBV MTCT in Senegal, especially at the decentralized level of the healthcare system, where $\mathrm{HCW}$ are responsible for both pre- and post-natal care, including routine HBV screening of pregnant women, pre- and post-test counseling and $\mathrm{HBV}$ vaccination at birth.

Several studies conducted on physicians, medicine students and non-medical HCW working in urban areas in sub-Saharan African countries have highlighted suboptimal overall knowledge of HBV prevention and care and related work practices [11-15]. In Senegal, a recent study conducted among physicians in the major hospitals in Dakar and St. Louis also highlighted that these professionals lacked training in viral hepatitis management [16]. HBV prevention and care bring acute and complex challenges to $\mathrm{HCW}$, especially in rural and decentralized areas where human and technical resources are scarce and where the population has limited financial resources and a low educational level $[17,18]$. However, these challenges are greatly underdocumented. Further studies on HCW working in decentralized and rural healthcare facilities are therefore required to investigate their adhesion to the WHO strategies introduced to reduce HBV vertical transmission, and to assess whether they are adequately trained and supported to implement these strategies effectively.

In this study, we aimed to investigate $\mathrm{HBV}$ prevention and care knowledge and practices of HCW working in two districts of the rural region of Fatick in Senegal, as well as challenges they faced to implement prevention activities related to HBV MTCT.

\section{Methods}

\section{Study setting}

Fatick is one of the 14 regions of the Senegal with 714,389 inhabitants. It is located $132 \mathrm{~km}$ east of Dakar, at the border with Gambia. The region is mostly rural with agricultural, livestock farming and fishing being its main resources. Maternal and child health indicators in the Fatick region are among the best in the country. In 2014, coverage for the pentavalent vaccine was $84 \%$ [19]. Furthermore, the region ranked third in the country for infant and child mortality rates (estimated at 52 and 73 per 1000, 
respectively) and fourth for maternal mortality rate (estimated at 365 per 1000) [20]. The Fatick region is divided into seven health districts with 110 healthcare facilities, including the regional hospital, 7 healthcare centers that constitute reference healthcare facilities for each district, and 102 primary healthcare posts which are first-contact facilities offering basic services including maternal and child healthcare as well as normal deliveries. The present study was conducted in two of the seven health districts: i) the Fatick district which includes the regional capital city of Fatick and has both the largest district-level population and the best healthcare infrastructure in the region and ii) the Niakhar district, which is a typical rural district of the region with limited health infrastructure and human resources. Together, both selected districts account for 37 of the 110 health facilities in the region (i.e. 34\%) and 274 of $597 \mathrm{HCW}$ (i.e. 46\%). Besides the regional hospital located in the capital, the 37 health facilities of the two districts comprise 2 healthcare centers and 34 primary healthcare posts.

This study area was chosen for the two following main reasons. First, the present study is nested within the ongoing research project AmBASS (ANRS 12356) which is being implemented in the area covered by the Niakhar Health and Demographic Surveillance System located in the Niakhar and Fatick districts. The AmBASS project is a large population-based survey which aims to study the epidemiology, and socioeconomic and public health impacts of HBV chronic infection in rural area in Senegal [21]. Second, the Fatick region has been chosen by the Senegalese National Hepatitis Program as a pilot region for the decentralization of HBV care and treatment, which makes this region particularly interesting given our study objectives [22].

\section{Study design}

We used a cross-sectional mixed-methods survey: the quantitative component sought to document both $\mathrm{HCW}$ global knowledge of HBV and HCW acceptability of interventions for prevention of MTCT (including screening of pregnant women and vaccination at birth), while the qualitative component explored HCW perceptions and field experience regarding these interventions, as well as the daily challenges they faced in implementing them.

The sample size for the quantitative component was optimized $(n=100)$ to both provide descriptive statistics and to take into account human resource and time constraints.

Two-stage reasoned sampling was used for the quantitative component of the survey as follows: in the first stage, we selected the healthcare facilities to include in the survey from the 37 healthcare facilities located in the
Niakhar and Fatick districts. To do this, a purposive approach was adopted using the following selection criteria in order to capture the diversity of the healthcare supply: location of the facility (urban versus rural area), level of decentralization (regional hospital, district healthcare center or primary healthcare post), and number of HCW working in each facility ( $<10$ versus $\geq 10)$. Accordingly, 15 facilities were selected as follows: the Fatick regional public hospital which has the largest maternity unit in the region, the 2 healthcare centers of the two districts (both public) and 12 primary healthcare posts (10 public and 2 private) (See Additional file 1). In the second stage, all eligible $\mathrm{HCW}$ in the 15 healthcare facilities chosen at first stage were invited to participate in the survey. Eligibility criteria were based on HCW roles and daily activities in the facilities. In the 12 primary healthcare posts, all $\mathrm{HCW}$ were eligible to participate in the survey as they had overlapping roles and duties given the small staffing numbers $(<10)$. In the two healthcare centers and in the regional hospital, where staff had better-defined roles and duties, only $\mathrm{HCW}$ in charge of general consultation, vaccination, pre- and post-natal consultations and deliveries were eligible.

The qualitative component of the survey was proposed to willing and available HCW who were eligible for the quantitative survey in the 15 selected facilities and whose characteristics represented all the categories of HCW participating in the quantitative survey. However, to avoid potential response bias, HCW could only participate in one component of the study (i.e. either in the qualitative or quantitative component). We also included one HCW working in a very well-known traditional health center which plays a key role in the care of the population living in the study area.

\section{Data collection}

Data collection was conducted between May 24th and July 6th 2017. Quantitative data on HCW characteristics were collected through face-to-face paper-based questionnaires structured around the following modules: i) socio-demographic characteristics, ii) training, experience and activities in the field of HBV, iii) knowledge about HBV natural history, epidemiology, screening, vaccination and treatment, and iv) acceptability and perception of MTCT prevention strategies (See Additional file 2). Most questions had only three possible answers ("yes", "no" and "I do not know"). Multimodal knowledge questions with one correct answer and several incorrect answers were also asked.

Qualitative data were collected using in-depth individual interviews conducted by a Master's degree student in international public health. The following themes were explored during semi-structured interviews: knowledge and representations of $\mathrm{HCW}$ about $\mathrm{HBV}$ infection 
(especially its transmission modes), experience in HBV screening, vaccination, treatment, and challenges faced in the implementation of these activities. The principle of data saturation was respected [23].

Questionnaire administration lasted on average 30 $\mathrm{min}$, and qualitative interviews between 19 and $52 \mathrm{~min}$. Quantitative data were collected mainly in French, the official language in Senegal. However, a local experienced translator helped translate questionnaires into Serer for HCW who had a low level of French (approximately 20 people). All qualitative interviews were conducted in French and audio-recorded with the participants' consent.

\section{Data analysis}

The study population of the quantitative component included HCW involved in activities related to maternal and child health. They were selected using seven questions documenting whether or not their routine work practice involved the following activities: i) prenatal care, ii) post-natal care, iii) deliveries and iv) vaccination. According to their answers to these questions, $\mathrm{HCW}$ were classified into two groups:

1) $\mathrm{HCW}$ mainly involved in prenatal care activities, i.e. those who reported they performed only prenatal consultations, and those who reported both prenatal consultations and at least one other activity from the following: postnatal care, deliveries or vaccination (Group 1);

2) $\mathrm{HCW}$ only involved in vaccination activities (Group 2).

Quantitative data on HCW knowledge, perceptions and practices concerning HBV were first described overall and then compared between the two groups of HCW using a Chi-square or Fisher's exact test for categorical variables, and Mann-Whitney test for continuous variables. To this end, binary knowledge variables were built by grouping correct answers against incorrect answers (including the "I do not know" answers) (Table 1). As there were few missing data $(<5 \%)$, descriptive analyses (number $(\%)$ and median [interquartile range, IQR]) were performed on complete data. R software (version 3.4.2) was used for the analyses.

Qualitative data analysis was based on grounded theory, which is an inductive research method suitable for the exploration of health care experience [24]. Recorded interviews were first transcribed and then analyzed using sequenced thematic coding, as described by Paillé and al [25].

\section{Results}

\section{Study population}

Of the 133 eligible HCW, 112 participated in the survey (101 and 11 in the quantitative and qualitative components, respectively), i.e. a global participation rate of $84 \%$. Reasons for non-participation included absence or unavailability at the time of the survey $(n=18,14 \%)$ and refusal to participate $(n=3,2 \%)$. Among the 101 participants in the quantitative component, based on their questionnaire answers, we excluded $14 \mathrm{HCW}$ who reported not being involved in prenatal or postnatal care, deliveries or vaccination (including 3 physicians) (Fig. 1). Accordingly, the study population in the quantitative component comprised $87 \mathrm{HCW}$. Its main characteristics are described in Table 2.

The majority were women (83\%) and median [IQR] age was 35 [30-40] years. More than half (53\%) had an education level higher than middle school. Approximately one third (33\%) were community healthcare workers, $29 \%$ registered or licensed professional nurses, 19\% nursing assistants, $17 \%$ midwives and $1 \%$ laboratory technicians. The median [IQR] duration of $\mathrm{HCW}$ professional experience was 7 [4-14] years. A majority (61\%) worked in primary healthcare posts, $30 \%$ in the two district healthcare centers and $9 \%$ in the regional hospital.

Forty-seven (54\%) HCW were mainly involved in prenatal care (Group 1) and $40(46 \%)$ exclusively in vaccination (Group 2). HCW were older in Group 2 than in Group 1 (37 [33-50] versus (32 [27-37]), $p=$ 0.006 ). They also had a lower educational level and were less qualified: only $28 \%$ had an educational level higher than middle school (versus $75 \%$ in Group 1, $p<10^{-3}$ ) and most (75\%) were community HCW or nursing assistants (versus 52\% in Group 1, $\mathrm{p}<10^{-3}$ ).

Of the $11 \mathrm{HCW}$ included in the qualitative component, 3 were physicians, 4 were nurses, 2 were midwives, 1 was a community healthcare worker and 1 was a laboratory technician. Six men and five women participated (Table 3).

\section{HCW general knowledge of hepatitis B \\ Natural history and epidemiology}

Overall, $81 \%$ of participating HCW were aware that a virus causes $\mathrm{HBV}, 94 \%$ knew that $\mathrm{HBV}$ affects the liver, and 80 and $85 \%$ knew that complications of HBV include cirrhosis and liver cancer, respectively (Table 4).

However, qualitative interviews showed that this basic knowledge was not always well understood. More specifically, the causes of HBV were confused with other risk factors of liver disease such as alcohol or peanut consumption:

- "The main cause of hepatitis B, in theory, is said to be alcoholism." (Interview HCW 11)

- "Others also say that there are peanuts. In places where you consume a lot of peanuts, there is a risk [of hepatitis B]" (Interview HCW 11)

Overall, $87 \%$ of HCW knew that HBV might be transmitted from mother to child during pregnancy and/or 
Table 1 Description of the knowledge variables and definition of correct answers

\begin{tabular}{|c|c|c|}
\hline Knowledge questions & Possible answers & Correct answer $^{\mathrm{a}}$ \\
\hline \multicolumn{3}{|c|}{ General knowledge of HBV (natural history and epidemiology) } \\
\hline \multirow{3}{*}{$\begin{array}{l}\text { What kind of infectious agent } \\
\text { causes hepatitis B? }\end{array}$} & Virus & \multirow[t]{3}{*}{ Virus } \\
\hline & Bacterium & \\
\hline & I do not know & \\
\hline \multirow[t]{5}{*}{ What organ is affected by HBV? } & Liver & \multirow[t]{5}{*}{ Liver } \\
\hline & Lung & \\
\hline & Stomach & \\
\hline & Heart & \\
\hline & I do not know & \\
\hline \multirow{2}{*}{$\begin{array}{l}\text { What complications can be caused } \\
\text { by hepatitis B? }\end{array}$} & Liver cancer (yes; no; I do not know) & Yes \\
\hline & Cirrhosis (yes; no; I do not know) & Yes \\
\hline \multirow{7}{*}{$\begin{array}{l}\text { What are the modes of HBV } \\
\text { transmission? }\end{array}$} & Dust (yes; no; I do not know) & No \\
\hline & Contaminated water (yes; no; I do not know) & No \\
\hline & $\begin{array}{l}\text { Perinatal transmission (from mother to child) } \\
\text { (yes; no; I do not know) }\end{array}$ & Yes \\
\hline & Breastfeeding (yes; no; I do not know) & No \\
\hline & $\begin{array}{l}\text { Horizontal transmission (during childhood through } \\
\text { contacts with infected blood) } \\
\text { (yes; no; I do not know) }\end{array}$ & Yes \\
\hline & $\begin{array}{l}\text { Percutaneous transmission or transmission through } \\
\text { mucosae (yes; no; I do not know) }\end{array}$ & Yes \\
\hline & Sexual transmission (yes; no; I do not know) & Yes \\
\hline \multirow{3}{*}{$\begin{array}{l}\text { Is perinatal transmission (from } \\
\text { mother-to-child) one of the main modes } \\
\text { of transmission in Senegal? }\end{array}$} & Yes & \multirow[t]{3}{*}{ Yes } \\
\hline & No & \\
\hline & I do not know & \\
\hline \multirow{4}{*}{$\begin{array}{l}\text { Are people infected by HBV during } \\
\text { childhood ( }<1 \text { year) going to develop } \\
\text { chronic infection? }\end{array}$} & Yes, more than $80 \%$ of them & \multirow[t]{4}{*}{$\begin{array}{l}\text { Yes, more than } \\
80 \% \text { of them }\end{array}$} \\
\hline & Yes, approximately $50 \%$ of them & \\
\hline & Yes, only $5 \%$ & \\
\hline & I do not know & \\
\hline \multicolumn{3}{|l|}{ Specific knowledge on HBV screening } \\
\hline \multirow{4}{*}{$\begin{array}{l}\text { What are the priority groups for which } \\
\text { routine screening of chronic hepatitis B } \\
\text { is recommended? }\end{array}$} & Pregnant women (yes; no; I do not know) & Yes \\
\hline & Blood donors (yes; no; I do not know) & Yes \\
\hline & Health Care Workers (yes; no; I do not know) & Yes \\
\hline & HIV-positive patients (yes; no; I do not know) & Yes \\
\hline \multirow{2}{*}{$\begin{array}{l}\text { What kind of test can be used to screen } \\
\text { for HBV in adults and children }>1 \text { year }\end{array}$} & Rapid diagnostic test (yes; no; I do not know) & Yes \\
\hline & Laboratory-based immunoassay (yes; no; I do not know) & Yes \\
\hline \multicolumn{3}{|l|}{ Specific knowledge on HBV vaccination } \\
\hline \multirow{3}{*}{$\begin{array}{l}\text { What are the potential strategies for } \\
\text { reducing perinatal transmission? }\end{array}$} & Vaccination at birth (yes; no; I do not know) & Yes \\
\hline & Antiviral treatment for the mother (yes; no; I do not know) & Yes \\
\hline & Immune globulin administration (yes; no; I do not know) & Yes \\
\hline \multirow[t]{4}{*}{$\begin{array}{l}\text { When should the first dose of HBV } \\
\text { vaccine be administered to children? }\end{array}$} & Within $24 \mathrm{~h}$ after birth & \multirow[t]{4}{*}{$\begin{array}{l}\text { Within } 24 \mathrm{~h} \\
\text { after birth }\end{array}$} \\
\hline & Within the first week of life & \\
\hline & At 6 weeks & \\
\hline & At 1 year old & \\
\hline
\end{tabular}


Table 1 Description of the knowledge variables and definition of correct answers (Continued)

\begin{tabular}{lll}
\hline Knowledge questions & Possible answers & Correct answer $^{\text {a }}$ \\
\hline $\begin{array}{l}\text { In total, how many injections arerequired } \\
\text { to immunize children against hepatitis B }\end{array}$ & I do not know & 3 or 4 injections \\
infection? & 2 injection & injections \\
& 3 injections \\
& 4 injections \\
& Other \\
Specific knowledge on HBV treatment & I do not know \\
Is there an effective treatment against & \\
chronic hepatitis B infection? & Yes \\
& No \\
Which of the following treatments has & I do not know \\
proven efficacy against chronic hepatitis & Lamivudine (yes; no; I do not know) \\
B infection? & Tenofovir (yes; no; I do not know) \\
How long does antiviral therapy against & Traditional treatment (yes; no; I do not know) \\
chronic hepatitis B infection continue? & 1 week \\
& A month \\
& For life \\
\hline
\end{tabular}

HBV hepatitis B virus

${ }^{a}$ All answers other than the correct one were recoded as incorrect

delivery (Table 4). However, other modes of transmission tended to be less correctly reported, especially in $\mathrm{HCW}$ involved in vaccination activities only (i.e., Group 2). More specifically, in this group, only 67,52 and $32 \%$ of HCW knew that HBV may be transmitted through, respectively, horizontal transmission, sexual transmission and percutaneous or mucous membranes (versus 85, 66 and $53 \%$ in $\mathrm{HCW}$ mainly involved in prenatal care (i.e., Group 1), $p=0.05, p=0.20$ and $p=0.05$, respectively) (Table 4). In addition, a substantial proportion of HCW reported incorrect HBV transmission modes: more than half (52\%) reported that HBV could be transmitted through breastfeeding, 29\% through contaminated water and $18 \%$ through dust.

Qualitative interviews also brought to light a large number of inaccurate beliefs about possible fecal-oral transmission, transmission from circulating air, and transmission from dirty hands.

- "So there are the body fluids, fecal-oral transmission is possible, if I'm not mistaken." (Interview HCW 1)

- "The modes of transmission, there's mother-to-child, sexual, blood, through circulating air." (Interview HCW 6)

- "There's sexual (transmission), there are also the factors of, the factors of... what are they called, not hereditary but, what are they called, like natural." (Interview HCW 11)
Basic knowledge of the epidemiology of HBV was also low. Only $51 \%$ of HCW knew that perinatal transmission is one of the main modes of HBV transmission in Senegal and only $24 \%$ knew that early acquisition is associated with a high risk (> 80\%) of developing chronic HBV infection (Table 4).

\section{Screening}

Specific knowledge, skills and capacities for HBV screening

Overall, HCW in both groups had good knowledge of priority groups for HBV screening. A large majority listed pregnant women (92\%), blood donors (87\%) and healthcare workers (82\%) but only (64\%) reported HIV-positive patients (Table 5). Knowledge of HBV screening tests was relatively low. Only 70 and 46\% knew that HBV could be screened using, respectively, rapid diagnostic tests (RDT) and laboratory-based immunoassays. $\mathrm{HCW}$ in Group 1 were significantly more likely to know that RDT can be used for HBV screening than $\mathrm{HCW}$ in Group 2 (81\% versus 57\%, $p=0.02$ ).

More than half (59\%) of $\mathrm{HCW}$ reported that they had already benefited from training in HBV infection, and $67 \%$ in general counseling techniques, yet only $20 \%$ had received specific HBV counseling training. Furthermore, HCW in Group 2 were significantly more likely to have received training than $\mathrm{HCW}$ in Group 1, both in HBV infection (respectively, 72\% 
Eligible population in the 37 healthcare facilities* of the two districts of Fatick and Niakhar $(\mathrm{N}=274)$

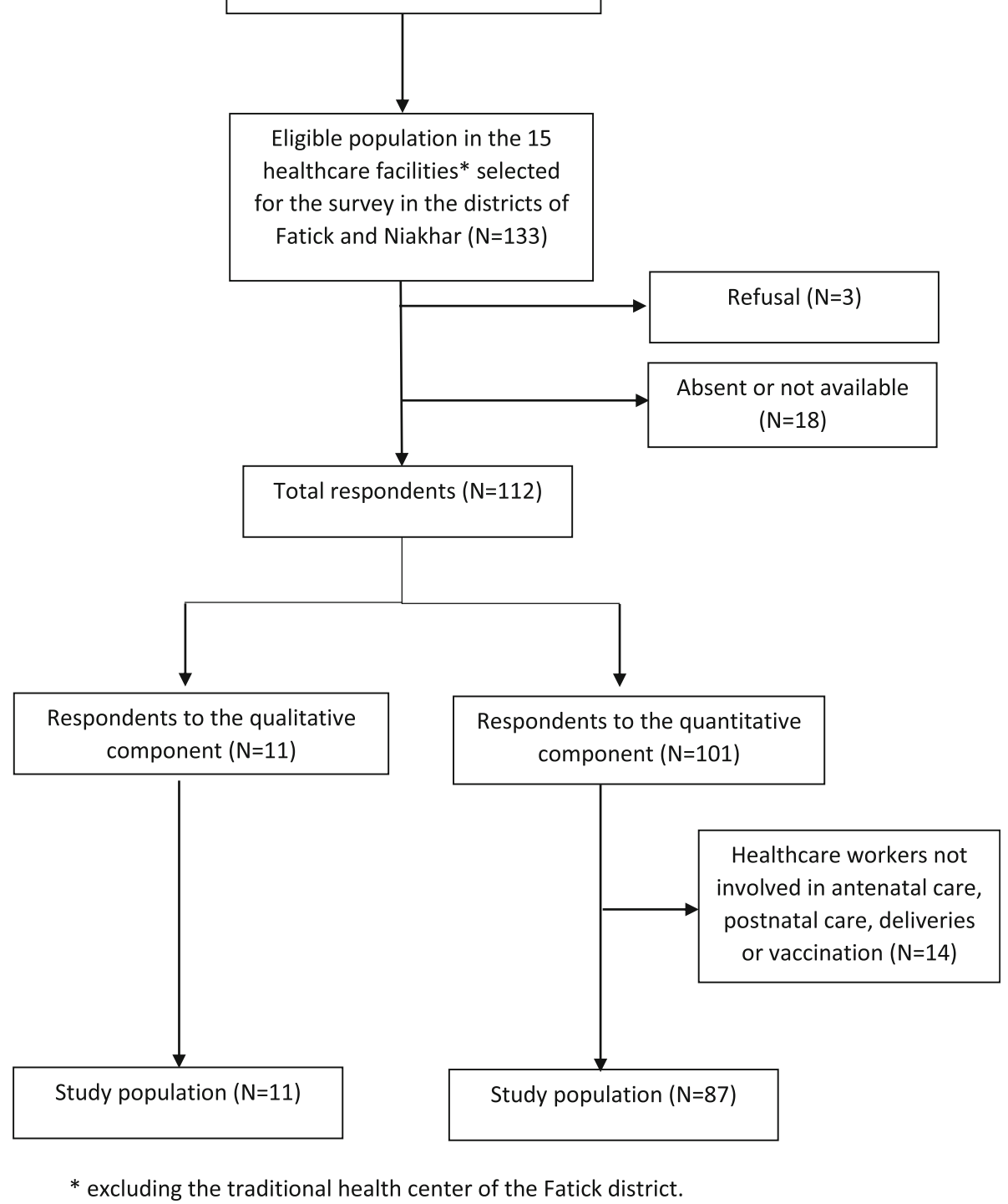

Fig. 1 Selection of the study population, $n=98$

versus $47 \%, p=0.01$ ) and in general counseling (respectively, $82 \%$ versus $54 \%, p=0.01$ ). Finally, $28 \%$ felt they were not adequately trained to correctly deliver counseling to HBV-positive patients.

\section{HCW acceptability of systematic screening in pregnant} women and perceived challenges to its implementation HCW acceptability of systematic screening in pregnant women was high, with $95 \%$ of participants reporting that screening is useful to prevent MTCT (Table 5). This was confirmed in qualitative interviews.
- "... It's to protect the child, so it's the only way to prevent the child from getting the disease." (Interview HCW 9)

- "First, we need to know the mother's status during antenatal consultations, [so we need to] do the analysis." (Interview HCW 5)

However, even though HCW favored systematic screening and counselling of pregnant women, only $68 \%$ of those in Group 1 and 25\% in Group $2\left(\mathrm{p}<10^{-3}\right)$ declared they had actually proposed such screening during the previous month (Table 5). 
Table 2 Characteristics of healthcare workers who participated in the quantitative survey $(n=87)$

\begin{tabular}{|c|c|c|c|c|}
\hline \multirow[t]{3}{*}{ Variable (\% of missing data) } & Total & $\begin{array}{l}\text { HCW mainly involved } \\
\text { in prenatal care activities } \\
\text { (Group 1) }\end{array}$ & $\begin{array}{l}\text { HCW involved exclusively } \\
\text { in vaccination activities } \\
\text { (Group 2) }\end{array}$ & \multirow[t]{3}{*}{$p$-value } \\
\hline & $(N=87)$ & $(N=47,54 \%)$ & $(N=40,46 \%)$ & \\
\hline & \multicolumn{3}{|c|}{$\mathrm{N}(\%)$ or median [IQR] } & \\
\hline Age (years) (4\%) & $35[30-40]$ & $32[27-37]$ & $37[33-50]$ & 0.006 \\
\hline \multicolumn{5}{|l|}{ Gender } \\
\hline Male & $15(17)$ & $6(13)$ & $9(22)$ & \\
\hline Female & $72(83)$ & $41(87)$ & $31(78)$ & 0.231 \\
\hline \multicolumn{5}{|l|}{ Education level } \\
\hline$\leq$ middle school & $41(47)$ & $12(25)$ & $29(72)$ & \\
\hline$>$ middle school & $46(53)$ & $35(75)$ & $11(28)$ & $<10^{-3}$ \\
\hline \multicolumn{5}{|l|}{ Initial training in the field of health or social care } \\
\hline Nurses (registered and licensed professional) & $25(29)$ & $16(34)$ & $9(22.5)$ & \multirow[t]{5}{*}{$<10^{-3}$} \\
\hline Nursing assistant & $17(19)$ & $7(15)$ & $10(25)$ & \\
\hline Midwife & $15(17)$ & $15(32)$ & $0(0)$ & \\
\hline Laboratory technician & $1(1)$ & 0 & $1(2.5)$ & \\
\hline Community healthcare worker & $29(33)$ & $9(19)$ & $20(50)$ & \\
\hline Professional experience (years) (1\%) & $7[4-14]$ & $5[3-10]$ & $11[7-17]$ & 0.001 \\
\hline \multicolumn{5}{|l|}{ Decentralization level of the healthcare facility } \\
\hline Regional hospital & $8(9)$ & $7(15)$ & $1(2)$ & \multirow[t]{3}{*}{0.150} \\
\hline District healthcare center & $26(30)$ & $13(28)$ & $13(33)$ & \\
\hline Primary healthcare post & $53(61)$ & $27(57)$ & $26(65)$ & \\
\hline
\end{tabular}

$H C W$ Healthcare Workers, HBV hepatitis B virus, IQR interquartile range

${ }^{a}$ Chi-square test or Fisher's exact test for categorical variables and Mann-Whitney test for continuous variables

Table 3 Characteristics of healthcare workers who participated in the qualitative survey $(n=11)$

\begin{tabular}{llll}
\hline Individual interview $n^{\circ}$ & Initial training & Healthcare facility type & Activity \\
\hline 1 & Physician & Regional hospital & Medical consultation \\
2 & Physician & Healthcare center & Medical consultation \\
3 & Physician & Regional hospital & Medical consultation \\
4 & Purse & Primary healthcare post & $\begin{array}{l}\text { Prenatal care activities, } \\
\text { routine consultation, } \\
\text { immunization }\end{array}$ \\
5 & Midwife & Primary healthcare post & $\begin{array}{l}\text { Prenatal care activities, } \\
\text { deliveries, immunization }\end{array}$ \\
7 & Midwife & Primary healthcare post & Prenatal care activities, deliveries \\
8 & Nurse & Healthcare center & $\begin{array}{l}\text { Prenatal care activities, routine } \\
\text { consultations, deliveries }\end{array}$ \\
9 & Community healthcare & Primary healthcare post & Prenatal care activities, routine \\
consultation, immunization & Prenatal care activities, routine \\
10 & Nurse & Primary healthcare post & consultations, deliveries \\
11 & Laboratory technician & Head of the traditional \\
\end{tabular}


Table 4 General knowledge of HBV (natural history and epidemiology) among healthcare workers participating in the quantitative component of the survey $(n=87)$

\begin{tabular}{|c|c|c|c|c|}
\hline \multirow[t]{3}{*}{ Variables (\% of missing data) } & \multirow{3}{*}{$\begin{array}{l}\text { Total } \\
(N=87)\end{array}$} & $\begin{array}{l}\text { HCW mainly involved in } \\
\text { prenatal care activities (Group 1) }\end{array}$ & \multirow{3}{*}{$\begin{array}{l}\text { HCW involved exclusively in } \\
\text { vaccination activities (Group 2) } \\
(N=40,46 \%)\end{array}$} & \multirow[t]{3}{*}{$p$-value ${ }^{a}$} \\
\hline & & $(N=47,54 \%)$ & & \\
\hline & & N (\%) & & \\
\hline \multicolumn{5}{|c|}{ What kind of infectious agent causes hepatitis B? (1\%) } \\
\hline Correct answer & $70(81)$ & $40(87)$ & $30(75)$ & \\
\hline Incorrect answer & $16(19)$ & $6(13)$ & $10(25)$ & 0.15 \\
\hline \multicolumn{5}{|c|}{ What organ is affected by HBV? (8\%) } \\
\hline Correct answer & $75(94)$ & $43(98)$ & $32(89)$ & \\
\hline Incorrect answer & $5(6)$ & $1(2)$ & $4(11)$ & 0.12 \\
\hline \multicolumn{5}{|c|}{ What complications can be caused by hepatitis B? } \\
\hline \multicolumn{5}{|l|}{ Liver cancer } \\
\hline Correct answer & $74(85)$ & $43(91)$ & $31(78)$ & 0.07 \\
\hline Incorrect answer & $13(15)$ & $4(9)$ & $9(22)$ & \\
\hline \multicolumn{5}{|l|}{ Cirrhosis (1\%) } \\
\hline Correct answer & $69(80)$ & $40(87)$ & $29(72)$ & \\
\hline Incorrect answer & $17(20)$ & $6(13)$ & $11(28)$ & 0.09 \\
\hline \multicolumn{5}{|c|}{ What are the modes of HBV transmission? } \\
\hline \multicolumn{5}{|l|}{ Dust (5\%) } \\
\hline Correct answer & $68(82)$ & $37(80)$ & $31(84)$ & 0.69 \\
\hline Incorrect answer & $15(18)$ & $9(20)$ & $6(16)$ & \\
\hline \multicolumn{5}{|l|}{ Contaminated water (1\%) } \\
\hline Correct answer & $61(71)$ & $34(72)$ & $27(69)$ & 0.75 \\
\hline Incorrect answer & $25(29)$ & $13(28)$ & $12(31)$ & \\
\hline \multicolumn{5}{|l|}{ Perinatal transmission } \\
\hline Correct answer & $76(87)$ & $41(87)$ & $35(87)$ & 0.65 \\
\hline Incorrect answer & $11(13)$ & $6(13)$ & $5(13)$ & \\
\hline \multicolumn{5}{|l|}{ Breastfeeding (1\%) } \\
\hline Correct answer & $41(48)$ & $22(47)$ & $19(49)$ & 0.86 \\
\hline Incorrect answer & $45(52)$ & $25(53)$ & $20(51)$ & \\
\hline \multicolumn{5}{|l|}{ Horizontal transmission } \\
\hline Correct answer & $67(77)$ & $40(85)$ & $27(67)$ & 0.05 \\
\hline Incorrect answer & $20(23)$ & $7(15)$ & $13(33)$ & \\
\hline \multicolumn{5}{|c|}{ Percutaneous transmission or transmission through mucosae (2\%) } \\
\hline Correct answer & $37(44)$ & $25(53)$ & $12(32)$ & 0.05 \\
\hline Incorrect answer & $48(56)$ & $22(47)$ & $26(68)$ & \\
\hline \multicolumn{5}{|l|}{ Sexual transmission } \\
\hline Correct answer & $52(60)$ & $31(66)$ & $21(52)$ & 0.20 \\
\hline Incorrect answer & $35(40)$ & $16(34)$ & $19(48)$ & \\
\hline \multicolumn{5}{|c|}{ Is perinatal transmission (from mother-to-child) one of the main modes of transmission in Senegal? (1\%) } \\
\hline Correct answer & $44(51)$ & $28(60)$ & $16(41)$ & \\
\hline Incorrect answer & $42(49)$ & $19(40)$ & $23(59)$ & 0.09 \\
\hline \multicolumn{5}{|c|}{ Are people infected by HBV during childhood (< 1 year) going to develop chronic infection? (2\%) } \\
\hline Correct answer & $19(24)$ & $13(29)$ & $6(15)$ & \\
\hline Incorrect answer & $66(76)$ & $32(71)$ & $34(85)$ & 0.12 \\
\hline
\end{tabular}


HCW mentioned several barriers to implementing systematic HBV screening in pregnant women. The first was that HBV testing was not free for pregnant women, unlike screening for other diseases, such as HIV and malaria. In addition, they mentioned that it is quite expensive, which can discourage some women. They suggested that HBV screening could be more effective in this resource-limited rural population if tests were free of charge.

- "The prenatal checkup is 9,000 CFA (i.e. 15.7 USD)... the screening fees; it's them [the pregnant women] that pay... You know, for HIV, you do not pay. If we could make hepatitis B screening free, that would be good for women and also for the population." (Interview HCW 4)

The second barrier described by HCW was the lack of availability of RDT in primary healthcare posts. Consequently, HCW have to refer pregnant women to the two district healthcare centers, which are located more than $5 \mathrm{~km}$ (i.e. approximately a one-hour walk) away for the majority of the population living in the districts of Fatick and Niakhar.

- "Hepatitis B, I don't have rapid tests, that's to say that the women that come here, I send them to the laboratory because I don't have the means to do screening and they get back to me with the results." (Interview $\mathrm{HCW}$ 5)

Finally, HCW mentioned their difficulties to communicate information about the disease to patients with a low educational level. Some HCW believed that less-educated patients do not have the skills to understand the risks and consequences of HBV.

- "In contrast, people who didn't go to school, well, you explain it to them as well as you can. Sometimes they do not even understand. I have received patients with viral hepatitis $B$ but I am sure they do not know what it is. I explain, I explain it to them each time, but they're not conscious of what it means." (Interview $\mathrm{HCW} 3$ )

\section{Vaccination at birth \\ Specific knowledge and skills}

Almost all HCW (98\%) correctly answered that vaccination at birth is a strategy for reducing perinatal transmission and $85 \%$ correctly answered that the first dose of HBV vaccine for children should be administered within $24 \mathrm{~h}$ after birth (Table 6). However, only 38\% knew that three to four doses of HBV vaccine are required to ensure immunization in children, including a monodose at birth followed by two to three supplementary doses.

\section{HCW acceptability of HBV vaccination at birth and} perceived challenges to its implementation

Overall, HCW were very confident about the efficacy of HBV vaccine: 93\% declared it is effective and $98 \%$ said it is safe (Table 6). In addition, 99\% agreed that vaccinating newborns within $24 \mathrm{~h}$ is useful and necessary. The high acceptability of the $\mathrm{HBV}$ vaccine was also highlighted during qualitative interviews.

- "This really is a vaccine coming along at the right time, so it's a really useful vaccine to prevent the disease. Especially when it is started right at birth. And we've seen that it's a very accessible vaccine because it is free." (Interview HCW 9)

However, some HCW expressed concern about the effectiveness and safety of the birth dose for the babies born from a HBV-positive mother.

- "At birth, we do it for all the babies. I wonder what the difference is between a baby whose mother is positive for $H B V$ antibodies and one whose $H B V$ antibody count is negative" (Interview HCW 6)

HCW also reported that child vaccination at birth was well accepted by mothers.

- "No, no, we don't have problems really with them. There is no refusal. Because they're also beginning to understand the usefulness and significance of these vaccines... we explain that this vaccine is to avoid this or that pathology and then they really understand." (Interview HCW 7)

Despite good acceptability of child vaccination at birth, only $75 \%$ of HCW in Group 2 and 68\% in Group 1 declared they had actually vaccinated newborns in the month before the survey (Table 6).

$\mathrm{HCW}$ mentioned home deliveries as a barrier to vaccination at birth, as babies born at home are not always taken to healthcare facilities within the first $24 \mathrm{~h}$ of life for postnatal care.

- "Now as part of prevention, giving the hepatitis vaccine at day zero, we need to sensitize women so that they give birth in the facilities, to limit home deliveries a little." (Interview HCW 2)

- "When a home delivery happens, people that come 24 hours after it, we include them in our vaccination schedule. We put them into 2 categories. Children vaccinated in the first 24 hours, and those vaccinated after the first 24 hours." (Interview HCW 7) 
Table 5 Knowledge, skills, capacity and acceptability of HBV screening among healthcare workers participating in the quantitative component of the survey $(n=87)$

\begin{tabular}{llll}
\hline Variables (\% of missing data) & Total & $\begin{array}{l}\text { HCW mainly involved } \\
\text { in prenatal care activities (Group 1) } \\
(N=47,54 \%)\end{array}$ & $\begin{array}{l}\text { HCW involved exclusively } \\
\text { in vaccination activities (Group 2) } \\
(N=40,46 \%)\end{array}$ \\
& $(N=87)$-value ${ }^{a}$ \\
& & $N(\%)$
\end{tabular}

Specific knowledge, skills and training on testing and counseling

What are the priority groups for which routine screening of chronic hepatitis B is recommended?

Pregnant women

Correct answer

Incorrect answer

Blood donors

Correct answer

Incorrect answer

HCW

Correct answer

HIV-positive patients

Correct answer

Incorrect answer
Incorrect answer

$\begin{array}{ll}80(92) & 44(94) \\ 7(8) & 3(6) \\ 75(87) & 39(83) \\ 12(13) & 8(17) \\ 71(82) & 39(83) \\ 16(18) & 8(17) \\ & \\ 56(64) & 32(68) \\ 31(36) & 15(32)\end{array}$

$31(36) \quad 15(32)$

What kind of test can be used to test for HBV in adults and children $>1$ year?

Rapid diagnostic test

Correct answer

$61(70) \quad 38(81)$

$23(57)$

Incorrect answer

$26(30) \quad 9(19)$

$40(46) \quad 25(53)$

15 (38)

$46(54) \quad 22(47)$

24 (62)

Incorrect answer

Have you already benefited from training in HBV?

Yes (in my initial training, in continued education)

$51(59) \quad 22(47)$

29 (72)

No or I do not know

$36(41) \quad 25(53)$

$11(28)$

Have you already had training in counseling or therapeutic education for other diseases? (2\%)

$\begin{array}{llll}\text { Yes } & 57(67) & 25(54) & 32(82)\end{array}$

Have you already had training in counseling or therapeutic education for hepatitis B? (2\%)
Yes
$17(20)$
$11(24)$
$6(15)$
No or I do not know
$68(80) \quad 35(76)$
$33(85)$

Do you feel you are trained well enough to provide adequate counseling to HBV-positive patients?
Yes (a lot, somewhat, a little)
63 (72) $\quad 38(81)$
25 (62)
No (not at all, I do not know)
$24(28) \quad 9(19)$
$15(38)$

Acceptability of systematic screening in pregnant women and practices

Do you think it is useful to systematically propose hepatitis B screening to pregnant women?
Yes (a lot, somewhat, a little)
$83(95) \quad 46(98)$
37 (92)
No (not at all, I do not know)
$4(5) \quad 1(2)$
$3(8)$

0.25

In the last month, have you proposed hepatitis B screening to pregnant women?
Yes (always, often)
$42(48) \quad 32(68)$
10 (25)
$45(52) \quad 15(32)$
30 (75)

$<10^{-3}$ 
$\mathrm{HCW}$ also reported that cold chain problems, including power outages or failures, posed a risk to vaccine efficacy and immunization activities.

- "[...] It is the cold chain that sometimes is not up to scratch, because there are outages, the cold chain is faulty sometimes. If we had been equipped with solar fridges, because there's always sun here, that could help." (Interview HCW 4)

Finally, they emphasized the difficulties associated with mothers' compliance with their children's vaccination schedule.

- "It's just that sometimes there are not educated, they forget the days of their appointments, they forget sometimes, but if we go to them to have them come, they come." (Interview HCW 4)

\section{Care and treatment \\ Specific knowledge}

Overall, basic knowledge on HBV treatment was poor in $\mathrm{HCW}$ (Table 7). Only 45\% correctly answered that effective treatment for chronic HBV exists, and only $38 \%$ knew that treatment for HBV is life-long. Moreover, only 10 and $7 \%$ knew that Tenofovir and Lamivudine, respectively, were effective treatments against HBV. In addition, the effectiveness of antiviral treatment in preventing perinatal transmission was not very well known: only $55 \%$ of $\mathrm{HCW}$ reported that this strategy was effective in reducing perinatal transmission.

Qualitative interviews further highlighted HCW lack of knowledge about HBV treatment, especially the existence of effective treatments to treat HBV.

"There is no specific treatment for the disease" (Interview $\mathrm{HCW}$ 7)

Some also believed that only symptomatic treatments are currently available.

"Because you know that viral diseases are difficult to treat. So, for hepatitis there's only symptomatic treatment because you cannot purify the blood as we say..." (Interview HCW 2)

Finally, some HCW believed that treatment for hepatitis B only consisted of antibiotics, as was the case for HIV before the introduction of antiretroviral therapy.

"... in principle, all the patients that come to us in the late stages, what the doctors do, they might take an antibiotic like Fleming, which is very powerful... by the way it's a new molecule we [HCW] use... there's
Ciphran, Flagyl, Erytromycin, etc. those are very powerful antibiotics that we use" (Interview HCW 11)

\section{Practical challenges in relation to access to $\mathrm{HBV}$ care and treatment}

$\mathrm{HCW}$ were aware of their lack of knowledge in management of HBV-infected individuals, explaining that they referred patients who screened HBV-positive (especially pregnant women) to specialists, and that their roles were limited to providing advice on diet and alcohol and tobacco consumption.

"Really, I don't know much. I send them to the doctor and if there is a treatment... I see they (doctors) ask for transaminases analyses and all that, to see how the liver is working. But I also ask women not to eat too many fatty foods, to avoid taking a lot of peanuts and stuff, in any case to avoid fatty foods." (Interview HCW 5)

"So what we can tell people is to go see a specialist sometimes. At the same time, we give them advice on lifestyle habits, to avoid consuming certain foodstuffs and all that, such as alcohol, tobacco, to avoid them above all, because they can really intensify the disease." (Interview HCW 7)

HCW also highlighted the frequent use of traditional medicine as a first-line treatment, which delayed linkage to care. They indicated that HBV-positive patients only go for hospital consultation when their condition becomes critical with no possible improvement.

"It's that most of all which makes the patients come at a late stage, because as soon as they see the signs, they'll go to see the traditional practitioner who is right beside them. And, as you know, that's what's going to aggravate the disease, with all that stuff they take... after the belly starts to bloat, the eyes, the kidneys are already wrecked and all that, it's at this terminal stage they often come to hospital" (Interview $H C W 3)$

"It's the first resort for hepatitis B, as I just said, the Serer [people] often say that maybe it's a dietary problem, so they turn to traditional medicine" (Interview $\mathrm{HCW}$ 9)

In addition, $\mathrm{HCW}$ mentioned a lack of access to HBV antiviral treatment, because of high cost and unavailability in most healthcare facility pharmacies, except for regional and national hospitals. Nevertheless, they indicated that in these hospitals, HBV antiviral treatment 
Table 6 Knowledge, skills and acceptability of HBV vaccination among healthcare workers participating in the quantitative component of the survey $(n=87)$

\begin{tabular}{|c|c|c|c|c|}
\hline \multirow[t]{3}{*}{ Variable (\% of missing data) } & Total & $\begin{array}{l}\text { HCW mainly involved } \\
\text { in prenatal care activities (Group 1) }\end{array}$ & $\begin{array}{l}\text { HCW only involved in } \\
\text { vaccination activities (Group 2) }\end{array}$ & $p$-value \\
\hline & $(N=87)$ & $(N=47,54 \%)$ & $(N=40,46 \%)$ & \\
\hline & \multicolumn{3}{|c|}{ N (\%) } & \\
\hline \multicolumn{5}{|l|}{ Specific knowledge and skills on vaccination } \\
\hline \multicolumn{5}{|c|}{ What are the potential strategies for reducing perinatal transmission? } \\
\hline \multicolumn{5}{|l|}{ Vaccination at birth } \\
\hline Correct answer & $85(98)$ & $46(98)$ & $39(97)$ & \\
\hline Incorrect answer & $2(2)$ & $1(2)$ & $1(3)$ & 0.71 \\
\hline \multicolumn{5}{|c|}{ When should the first dose of HBV vaccine be administered to children? } \\
\hline Correct answer & $74(85)$ & $40(85)$ & $34(85)$ & 0.99 \\
\hline Incorrect answer & $13(15)$ & $7(15)$ & $6(15)$ & \\
\hline \multicolumn{5}{|c|}{ In total, how many injections are required to immunize children against hepatitis B infection? } \\
\hline Correct answer & $33(38)$ & $19(40)$ & $26(65)$ & 0.60 \\
\hline Incorrect answer & $54(62)$ & $28(60)$ & $14(35)$ & \\
\hline \multicolumn{5}{|c|}{ Acceptability of HBV vaccination at birth and practices } \\
\hline \multicolumn{5}{|c|}{ In your opinion, how effective is the hepatitis B vaccine? (1\%) } \\
\hline Very effective (> 95\%) or moderately & $80(93)$ & $43(94)$ & $37(92)$ & 0.59 \\
\hline Quite ineffective, I do not know & $6(7)$ & $3(6)$ & $3(8)$ & \\
\hline \multicolumn{5}{|c|}{ Do you agree that the hepatitis B vaccine is safe? } \\
\hline Strongly agree or rather agree & $85(98)$ & $45(96)$ & $40(100)$ & 1 \\
\hline $\begin{array}{l}\text { Neither agree or disagree, disagree } \\
\text { (rather or strongly), I do not know }\end{array}$ & $2(2)$ & $2(4)$ & 0 & \\
\hline \multicolumn{5}{|c|}{ Do you think it is useful to vaccinate newborns against hepatitis B within $24 \mathrm{~h}$ after birth? } \\
\hline Yes (a lot, somewhat) & $86(99)$ & $47(100)$ & $39(97)$ & \\
\hline A little, not at all, I do not know & $1(1)$ & 0 & $1(3)$ & 0.45 \\
\hline \multicolumn{5}{|c|}{ In the past month, have you vaccinated newborns against hepatitis B within $24 \mathrm{~h}$ of their birth? } \\
\hline Yes & $62(71)$ & $32(68)$ & $30(75)$ & 0.48 \\
\hline No or I do not know & $25(29)$ & $15(32)$ & $10(25)$ & \\
\hline
\end{tabular}

HCW Healthcare workers, HBV hepatitis B virus

${ }^{a}$ Chi-square test or Fisher's exact test

was provided free of charge only to HIV-HBV co-infected patients, and that HBV mono-infected patients did not have easy access to it.

"Antivirals are not really accessible to everyone.

This molecule is available only for patients living with HIV. These patients living with HIV who are infected with hepatitis $B$ are treated. However, mono-infected patients are left out because they are not entitled to Tenofovir, which is intended for HIV patients. That is the problem. Because if you need to buy the molecule, it is expensive. Sometimes it is not available in pharmacies. That is the problem" (Interview $\mathrm{HCW}$ 3)
Finally, in addition to the cost of drugs, $\mathrm{HCW}$ mentioned that HBV-positive patients must shoulder high costs of multiple medical examinations as part of their follow-up and treatment.

"Often, when you follow the patients, with countless required check-ups, ultrasounds, hepatic check-ups to be done again and again, at a certain point that leads to a problem of financial means. So really, it is about a lack of means" (Interview HCW 1)

"These patients that we receive, the balance sheet is also extremely steep, the antibodies, all this to follow the evolution of the disease, are extremely expensive, they are not really accessible to all" (Interview $\mathrm{HCW} 3$ ) 
Table 7 Knowledge of HBV care and treatment among healthcare workers participating in the quantitative component of the survey $(n=87)$

\begin{tabular}{|c|c|c|c|c|}
\hline \multirow[t]{3}{*}{ Variables (\% of missing data) } & Total & $\begin{array}{l}\text { HCW mainly involved in } \\
\text { prenatal care activities (Group 1) }\end{array}$ & $\begin{array}{l}\text { HCW involved exclusively in } \\
\text { vaccination activities (Group 2) }\end{array}$ & \multirow[t]{3}{*}{$p$-value } \\
\hline & $(N=87)$ & $(N=47,54 \%)$ & $(N=40,46 \%)$ & \\
\hline & \multicolumn{3}{|c|}{ N (\%) } & \\
\hline \multicolumn{5}{|c|}{ Is there an effective treatment against chronic hepatitis B infection? (2\%) } \\
\hline Correct answer & $38(45)$ & $17(37)$ & $21(54)$ & \multirow[t]{2}{*}{0.12} \\
\hline Incorrect answer & $47(55)$ & $29(63)$ & $18(46)$ & \\
\hline \multicolumn{5}{|c|}{ How long does antiviral therapy against chronic hepatitis B continue? (1\%) } \\
\hline Correct answer & $33(38)$ & $21(46)$ & $12(30)$ & \multirow[t]{2}{*}{0.12} \\
\hline Incorrect answer & $55(62)$ & $25(54)$ & $28(70)$ & \\
\hline \multicolumn{5}{|c|}{ Which of the following treatments has proven efficacy against chronic hepatitis B infection? } \\
\hline \multicolumn{5}{|l|}{ Lamiduvine (3\%) } \\
\hline Correct answer & $6(7)$ & $4(9)$ & $2(5)$ & \multirow[t]{2}{*}{0.41} \\
\hline Incorrect answer & $78(93)$ & $41(91)$ & $37(95)$ & \\
\hline \multicolumn{5}{|l|}{ Tenofovir (5\%) } \\
\hline Correct answer & $8(10)$ & $5(11)$ & $3(8)$ & \multirow[t]{2}{*}{0.43} \\
\hline Incorrect answer & $75(90)$ & $39(89)$ & $36(92)$ & \\
\hline \multicolumn{5}{|c|}{ What are the potential strategies for reducing perinatal transmission? } \\
\hline \multicolumn{5}{|c|}{ Antiviral treatment for the mother (1\%) } \\
\hline Correct answer & $47(55)$ & $28(60)$ & $19(49)$ & \multirow[t]{2}{*}{0.21} \\
\hline Incorrect answer & $39(45)$ & $19(40)$ & $20(51)$ & \\
\hline \multicolumn{5}{|c|}{ Immune globulin administration (2\%) } \\
\hline Correct answer & $20(23)$ & $10(21)$ & $10(26)$ & \multirow[t]{2}{*}{0.79} \\
\hline Incorrect answer & $65(77)$ & $37(79)$ & $28(74)$ & \\
\hline
\end{tabular}

HCW Healthcare workers, HBV hepatitis B virus

${ }^{a}$ Chi-square test or Fisher's exact test

\section{Discussion}

Using a comprehensive mixed-methods approach, this is the first study to explore knowledge, perceptions, acceptability, barriers and levers related to HBV prevention strategies among HCW working at the decentralized level of the healthcare system in the rural region of Fatick in Senegal.

\section{Overview of the results}

Three main findings emerged from the interviews with the HCW. First, HCW knowledge of key areas of HBV prevention and care - including transmission routes, screening options, prevention means and the existence of effective life-long treatment - seemed to be insufficient to provide adequate prevention and care interventions. This knowledge gap tended to be greater in HCW involved only in vaccination activities than in those involved mainly in prenatal care. Second, quantitative and qualitative data suggested high acceptability by HCW of systematic screening for $\mathrm{HBV}$ in pregnant women and HBV vaccination at birth in newborns, as well as positive perceptions about the efficacy and safety of vaccination. However, the implementation of these key interventions in routine care appeared to be suboptimal, as suggested by the significant proportion of HCW involved in prenatal care and/or vaccination activities who reported they had not performed either intervention during the previous month. Finally, our study highlighted some important barriers that may explain the suboptimal implementation of $\mathrm{HBV}$ prevention strategies and that may limit their effectiveness for preventing HBV MTCT. A significant proportion of $\mathrm{HCW}$ reported they had received no training on hepatitis $B$ infection and/or on pre- and post-HBV test counseling. This is supported by the low level of knowledge observed in the survey participants. Other important barriers highlighted were the lack of available and free HBV RDT, the non-availability of antiviral treatment for pregnant women diagnosed HBV-positive, and missed opportunities for vaccination at birth because of home deliveries.

\section{HCW knowledge about HBV natural history,} epidemiology, screening, vaccination and treatment HCW lack of knowledge about HBV infection and its epidemiology is consistent with previous studies conducted in 
caregivers with similar profiles but working in urban health facilities in sub-Saharan Africa endemic areas, especially Ethiopia and Cameroon [14, 26]. In those studies, only approximately half of the $\mathrm{HCW}$ had a sound knowledge of hepatitis B infection. Furthermore, as in our study, the main transmission routes were not well known: a non-negligible proportion of HCW thought that HBV could be transmitted through the fecal-oral route (20\% in Ethiopia and 44\% in Cameroon) and did not know that HBV could be transmitted from mother to child (34\% in Ethiopia). HCW knowledge on treatment for chronic HBV infection has been rarely investigated until now which is a reflection of the very limited access to and availability of HBV treatment in sub-Saharan Africa endemic areas. In a recent study conducted on Senegalese physicians working in the major hospitals of the two main cities of the country, $80 \%$ of the participants knew about the existence of an effective HBV treatment, 30\% correctly answered that it is a life-long treatment, and 51 and 57\%, respectively, identified lamivudine and tenofovir as HBV treatments [16]. These percentages were larger than those observed in our survey. However, ours did not include physicians.

Good knowledge of HBV infection, especially its epidemiology, transmission routes and treatment options, is essential to i) promote adherence to screening and vaccination schedule, ii) provide adequate counseling, and iii) refer positive cases to appropriate care. Our findings strongly suggest that inadequate training of $\mathrm{HCW}$ may hinder the effective implementation of HBV screening in pregnant women. Indeed, despite good acceptability of this key strategy, HCW felt insufficiently trained to deliver adequate counseling to HBV-positive patients. A study in Burkina Faso highlighted that poor HBV knowledge among HCW is a major barrier to linkage to HBV care [25]. Although $\mathrm{HCW}$ at decentralized levels are not responsible for HBV care or treatment in Senegal, they constitute the gateway to the specialist care currently delivered in major hospitals in the country. They therefore play an important role at the district level in screening cases, particularly pregnant women, and in linkage to care of HBV-positive individuals. Our results suggest there is an urgent need to improve HBV-related capacity building in HCW working at the decentralized level of the healthcare system, as they are the first line of healthcare for the population, especially in lowresource, rural and underserved areas.

\section{Challenges faced by HCW to implementing prevention activities and policy recommendations}

In our study, HCW reported a number of other barriers that may explain the suboptimal implementation of HBV prevention activities, including the high cost of screening and lack of RDTs in primary health posts. This is especially true for pregnant women, the consequence being that they need to travel to a healthcare facility equipped with a laboratory for HBV screening. Although HBV testing is included in prenatal tests prescribed during pregnancy, it is not free (unlike for HIV or malaria) and costs approximately 5.26 USD. In addition, the full prenatal check-up including blood count, blood group, glycaemia and Hbs antigen testing - costs 15.78 USD. Consequently, pregnant women do not always perform all the tests prescribed. This means that those who are HBV-positive may not be aware they are infected and risk transmitting HBV to their baby. The provision of free HBV RDT for pregnant women at the decentralized level is indispensable to ensure early diagnosis and in turn prevent HBV transmission. With regard to the implementation of vaccination at birth, our results are consistent with the $\mathrm{WHO}$ data which estimated that, in 2017 , only $50 \%$ of newborns in Senegal received HBV vaccine at birth [27]. The home birth rate there, estimated at $22 \%$, is a potential barrier to achieving high vaccination rates at birth [28]. Simple community interventions, such as the use of community health volunteers to inform health facilities of all home births and more effective interpersonal communication as recommended by WHO, could improve the current situation [29].

\section{Study limitations}

Some limitations of our study need to be acknowledged. First, self-reports of systematic screening and vaccination at birth can be affected by social desirability bias. HCW may have overemphasized the importance of screening pregnant women for HBV and of vaccinating newborns. However, the mixedmethods approach used here enabled us to investigate $\mathrm{HCW}$ perceptions on $\mathrm{HBV}$ prevention strategies in depth. It also helped us to understand challenges faced by HCW in the implementation of MTCT prevention activities which may explain the suboptimal implementation of these strategies [30]. Moreover, the mixed-methods approach is known to increase the reliability of data collected when the research topic is sensitive in nature, as may have been the case here: in the quantitative component of the survey, HCW may have seen the study as an examination of their knowledge [31].

Second, we used a two-stage reasoned sampling approach and not a random sampling method for the quantitative component. However, we believed the risk of selection bias is limited for the following reasons: i) the sample of healthcare facilities, selected based on a purposive approach, was quite representative of the diversity of the healthcare supply in the two study districts and in the Fatick region (see Additional file 1); ii) participation in the survey was proposed to all eligible HCW in the study area; and iii) $84 \%$ of eligible HCW finally participated in the survey.

Third, the relatively small sample size may have limited statistical power to detect significant inter-group differences 
in knowledge about HBV, acceptability and perceptions of prevention and care strategies. However, it is comparable with the sample size of similar surveys conducted among HCW in sub-Saharan Africa [16, 32]. Moreover, the present study was conducted in two districts of the region of Fatick, which account for 37 of all 110 healthcare facilities in the region (i.e. 34\%) and 274 of 597 (46\%) HCW. Although the study results cannot be generalized for the whole of Senegal, as they may not be representative of other districts and regions, they do provide quite a good picture of $\mathrm{HCW}$ knowledge, perceptions and challenges related to the implementation of HBV prevention and care activities in the Fatick region. Our study is particularly relevant to Senegal, as Fatick has been selected by the national hepatitis program as a pilot region for the decentralization of HBV care. The work here will also provide a good basis for further exploration of issues related to decentralization in other subSaharan African countries.

\section{Conclusions}

Despite the study's limitations, our findings may inform public-health decision-making on HBV prevention in rural Senegal. We found that most HCW working in decentralized health facilities do not have sufficient knowledge about HBV to enable them to carry out HBV prevention activities effectively, especially regarding prevention of MTCT. Similarly, despite the high level of acceptability of systematic screening for pregnant women and vaccination at childbirth by HCW, several structural barriers hamper the implementation of these strategies. There is an urgent need for health authorities to strengthen HBV prevention and care activities at the decentralized level of the Senegalese health care system. First, HCW must be trained up on the key areas of HBV infection, especially transmission routes, prevention means and treatment options. Second, access to HBV screening for pregnant women needs to be facilitated by providing RDT free of charge and making HBV treatment available for HBV-positive mothers. Finally, effective community-based interventions should be implemented to identify homebirths and guarantee timely vaccination.

\section{Additional files}

Additional file 1: Main characteristics of healthcare facilities: i) in the Fatick region $(N=110)$, ii) in the two selected districts of Fatick and Niakhar $(N=37)$ and iii) in the study sample $(N=15)$. Compares the main characteristics of the healthcare facilities selected in the study sample with that of the healthcare facilities of the Fatick and Niakhar districts and of the Fatick region. (DOCX $16 \mathrm{~kb}$ )

Additional file 2: Quantitative questionnaire. Presents the questionnaire which has been developed for the quantitative component of the study. (DOCX $24 \mathrm{~kb}$ )

\section{Abbreviations}

EPI: Expanded Immunization Program; HBV: Hepatitis B Virus;

HCW: Healthcare workers; HIV: Human Immunodeficiency Virus; IQR: Interquartile Range; MD: Missing data; MTCT: Mother-To-Child

Transmission; RDT: Rapid Diagnostic Test; WHO: World Health Organization

\section{Acknowledgements}

We thank our partners at the National Program on viral hepatitis and Ministry of Health and Social Action in Senegal, as well as all the healthcare workers who accepted to participate in the study. We also thank the French National Agency for Research on HIV/AIDS and viral hepatitis for its financial support and the Excellence Initiative of Aix-Marseille University - A*MIDEX, a French "Investissements d'Avenir" programme" for its funding of the PhD grant of TD. Finally, we thank Jude Sweeney for revising and editing the English version of the manuscript.

ANRS 12356 AmBASS study group

Cyril Bérenger, Marwan al Qays Bousmah, Sylvie Boyer, Patrizia Carrieri, Marion Coste, Maëlle de Sèze, Tchadine Djaogol, Gwenaëlle Maradan, Fabienne Marcellin, Carole Treibich (SESSTIM, UMR 1252 INSERM-IRD-

Université Aix Marseille, Marseille, France). Elhadji Ba, Aldiouma Diallo, Fambaye Dièye, Assane Diouf, Elhadji Bilal Faye, Assane Ndiaye, Lauren Perieres, Cheikh Sokhna (VITROME, UMR 257, Institut de Recherche pour le Développement, Dakar, Sénégal). Coumba Touré Kane, Gora Lo, Anna Julienne Selbé Ndiaye (Institut de Recherche en Santé, de Surveillance Epidémiologique et de Formation, Dakar, Sénégal). Philippe Halfon, Sofiane Mohamed (Hôpital Européen, Marseille, France). Nicolas Rouveau, Maria-Camila Calvo Cortès, Gabrièle Laborde-Balen (France REcherche Nord\&Sud Sida-hiv Hépatites, Paris, France).

Scientific advisory board

Martine Audibert, Fatou Fall, Ibrahima Gueye, Karine Lacombe, Moussa Seydi, Yusuke Shimakawa, Edouard Tuaillon, Muriel Vray.

\section{Authors' contributions}

TD conducted the literature review, designed the data collection tools, collected data on the field, analyzed and interpreted the data and co-wrote the first draft of the manuscript. MC contributed to the interpretation of data and drafting of the manuscript. FM and AJ made substantial contributions to the study conception and design, analysis and interpretation of quantitative data. FC and TGV made substantial contributions to the study conception and design, analysis and interpretation of qualitative data. AD made substantial contributions to the study conception, design and implementation. PMC made substantial contributions to all the steps of the study. SB designed the study, overviewed all the steps of the study and was a major contributor in writing the manuscript. All authors revised the article critically for important intellectual content, and approved the final version of the manuscript for submission.

\section{Funding}

This study is part of the research project AmBASS funded by the French National Agency for Research on HIV/AIDS and viral hepatitis (ANRS, grant 12356) and coordinated by the SESSTIM UMR 1252 and VITROME UMR 257. TD has received a PhD grant from Excellence Initiative of Aix-Marseille University - A*MIDEX, a French "Investissements d'Avenir" programme". The funders had no role in study design, data collection and analysis, decision to publish, or preparation of the manuscript. The findings and conclusions presented in this manuscript are those of the authors.

\section{Availability of data and materials}

The datasets used and/or analyzed during the current study are available from the corresponding author on reasonable request.

Ethics approval and consent to participate

This study was conducted in compliance with international and national regulations on ethics and research on people, and was approved by the national committee for health research of Senegal (approval reference: SEN 17/15). All participants were informed about the study's objective and its modalities and all provided written consent to participate. 


\section{Competing interests}

The authors declare that they have no competing interests.

\begin{abstract}
Author details
${ }^{1}$ Aix Marseille Univ, INSERM, IRD, SESSTIM, Sciences Economiques \& Sociales de la Santé \& Traitement de l'Information Médicale, Marseille, France. ${ }^{2}$ ORS PACA, Observatoire régional de la santé Provence-Alpes-Côte d'Azur, Marseille, France. ${ }^{3}$ INSERM U1219, ISPED, Université de Bordeaux, Bordeaux, France. ${ }^{4}$ Centre Population et Développement (CEPED), French Institute for Research on Sustainable Development (IRD), Université de Paris, INSERM SAGESUD, Paris, France. ${ }^{5}$ Emerging Diseases Epidemiology Unit, Pasteur Institute, Paris, France. ${ }^{6}$ VITROME UMR 257 Institut de Recherche Pour le Développement, Dakar, Senegal.
\end{abstract}

Received: 28 January 2019 Accepted: 9 August 2019

Published online: 04 September 2019

\section{References}

1. WHO. Global Hepatitis Report, 2017. Available at: https://www.who.int/ hepatitis/publications/global-hepatitis-report2017/en/ [Accessed 19 Feb 2018].

2. WHO. Hepatitis B, Key facts. Available at: https://www.who.int/news-room/ fact-sheets/detail/hepatitis-b [Accessed 19 Feb 2018].

3. Schweitzer A, Horn J, Mikolajczyk RT, Krause G, Ott JJ. Estimations of worldwide prevalence of chronic hepatitis B virus infection: a systematic review of data published between 1965 and 2013. Lancet Lond Engl. 2015; 386(10003):1546-55.

4. Edmunds WJ, Medley GF, Nokes DJ, Hall AJ, Whittle HC. The influence of age on the development of the hepatitis B carrier state. Proc Biol Sci. 1993; 253(1337):197-201.

5. Custer B, Sullivan SD, Hazlet TK, lloeje U, Veenstra DL, Kowdley KV. Global epidemiology of hepatitis B virus. J Clin Gastroenterol. 2004;38(10 Suppl 3):S158-68.

6. Shimakawa Y, Yan H-J, Tsuchiya N, Bottomley C, Hall AJ. Association of early age at establishment of chronic Hepatitis B infection with persistent viral replication, liver cirrhosis and hepatocellular carcinoma: a systematic review. PLOS ONE. 2013:8(7):e69430.

7. Shimakawa Y, Lemoine M, Bottomley C, Njai HF, Ndow G, Jatta A, et al. Birth order and risk of hepatocellular carcinoma in chronic carriers of hepatitis $B$ virus: a case-control study in the Gambia. Liver Int Off J Int Assoc Study Liver. 2015:35(10):2318-26.

8. $\mathrm{WHO} \mid$ Guidelines for the prevention, care and treatment of persons with chronic hepatitis B infection 2015. WHO. Available at: http://www.who.int/ hepatitis/publications/hepatitis-b-guidelines/en/[Accessed 21 Feb 2018].

9. WHO | Guidelines on hepatitis B and C testing 2017. WHO. Available at: http://www.who.int/hepatitis/publications/guidelines-hepatitis-c-b-testing/ en/[Accessed 21 Feb 2018].

10. Ministère de la Santé et de l'Action Sociale. Plan Pluri Annuel Complet (PPAC) du PEV 2012-2016. Sénégal; 2013. http://www. nationalplanningcycles.org/sites/default/files/planning_cycle_repository/ senegal/ppac_revise_vs_21juil2013_sen.pdf. Accessed 17 Apr 2019.

11. Mesfin YM, Kibret KT. Assessment of knowledge and practice towards hepatitis B among medical and health science students in Haramaya University, Ethiopia. PLoS One. 2013:8(11):e79642.

12. Abdela A, Woldu B, Haile K, Mathewos B, Deressa T. Assessment of knowledge, attitudes and practices toward prevention of hepatitis B virus infection among students of medicine and health sciences in Northwest Ethiopia. BMC Res Notes. 2016:9(1):410.

13. Tatsilong HOP, Noubiap JJN, Nansseu JRN, Aminde LN, Bigna JJR, Ndze VN, et al. Hepatitis B infection awareness, vaccine perceptions and uptake, and serological profile of a group of health care workers in Yaoundé, Cameroon. BMC Public Health. 2016:15(03):706.

14. Ogoina D, Pondei K, Adetunji B, Chima G, Isichei C, Gidado S. Prevalence of hepatitis B vaccination among health care workers in Nigeria in 2011-12. Int J Occup Environ Med. 2014;5(1):51-6.

15. Adjei CA, Asamoah R, Atibila F, Ti-Enkawol GN, Ansah-Nyarko M. Mother-tochild transmission of hepatitis B: extent of knowledge of physician's andmidwives in eastern region of Ghana. BMC Public Health. 2016;16:537.

16. Jaquet $A$, Wandeler $G$, Tine J, Diallo MB, Manga NM, Dia NM, et al. Prevention and Care of Hepatitis B in Senegal; awareness and attitudes of medical practitioners. Am J Trop Med Hyg. 2017:97(2):389-95.
17. Giles-Vernick T, Hejoaka F, Sanou A, Shimakawa Y, Bamba I, Traoré A. Barriers to linkage to Care for Hepatitis B Virus Infection: a qualitative analysis in Burkina Faso, West Africa. Am J Trop Med Hyg. 2016;95(6):1368-75.

18. Chabrol F, Noah DN, Tchoumi EP, Vidal L, Kuaban C, Carrieri MP, et al. Screening, diagnosis and care cascade for viral hepatitis B and C in Yaoundé, Cameroon: a qualitative study of patients and health providers coping with uncertainty and unbearable costs. BMJ Open. 2019;9(3):e025415.

19. République du Sénégal | Ministère de l'économie, des finances et du plan | agence nationale de la statistique et de la démographie | Situation économique et sociale régionale 2014. Aout 2017. Available at: http://www. ansd.sn/ressources/ses/SES-FATICK_2014.pdf. [Accessed 20 May 2019].

20. République du Sénégal | Ministère de l'économie, des finances et du plan | agence nationale de la statistique et de la démographie. Available at: http://unw.ansd.sn/ ressources/ses/chapitres/4-sante-Fatick2013.pdf. [Accessed 22 May 2019].

21. Coste M, De Sèze M, Diallo A, Carrieri MP, Marcellin F, Boyer S, ANRS 12356 AmBASS Study Group. Burden and impacts of chronic hepatitis B infection in rural Senegal: study protocol of a cross-sectional survey in the area of Niakhar (AmBASS ANRS 12356). BMJ Open. 2019;9(7):e030211. https://doi. org/10.1136/bmjopen-2019-030211.

22. Ministère de la Santé et de l'Action Sociale du Sénégal. « Célébration de la Journée mondiale de lutte contre I'hépatite : la décentralisation en exhergue ». DAKARACTU.COM. Available at: http://hepatites.sn/index.php/ medias/actualites/item/230-celebration-de-la-journee-mondiale-de-luttecontre-l-hepatite-la-decentralisation-en-exhergue [Accessed 20 May 2019].

23. Charmaz K. Constructing grounded theory: a practical guide through qualitative analysis. London: Sage; 2006.

24. Méliani V. Choisir l'analyse par théorisation ancrée: illustration des apports et des limites de la méthode. Recherche Qualitative du Singulier A L'Universel -hors serie - numero 15v; 2013.

25. Paillé $P$, Mucchielli A. L'analyse qualitative en sciences humaines et sociales. Paris: Armand Colin; 2012

26. Abeje G, Azage M. Hepatitis B vaccine knowledge and vaccination status among health care workers of Bahir Dar City Administration, Northwest Ethiopia: a cross sectional study. BMC Infect Dis. 2015;15:30

27. Global Health Observatory visualizations. Immunization coverage country punchcards. World Health Organization. Available at: http:// apps.who.int/gho/data/node.wrapper.immunization-cov?x-country=SEN [Accessed 1 Feb 2018]. WHO.

28. Faye $\mathrm{A}$, Niane $\mathrm{M}, \mathrm{Ba}$ I. Home birth in women who have given birth at least once in a health facility: contributory factors in a developing country. Acta Obstet Gynecol Scand nov. 2011;90(11):1239-43.

29. WHO. Hepatitis B Control Through Immunization: A reference Guide.2014. Available at: http://www.who.int/immunization/sage/meetings/2015/ october/8 WPRO Hepatitis B Prevention_Through_Immunization Regional_Reference_Guide.pdf [Accessed 11 June 2018].

30. Johnson RB, Onwuegbuzie AJ, Turner LA. Toward a definition of mixed methods research. J Mixed Methods Res. 2007;1:123.

31. Creswell JW, Plano Clark V. Designing and conducting research methods. 2nd ed. Los Angeles: Sage; 2011.

32. Debes JD, Kayandabila J, Pogemiller H. Knowledge of Hepatitis B transmission risks among health Workers in Tanzania. Am J Trop Med Hyg. 2016;94(5):1100-2.

\section{Publisher's Note}

Springer Nature remains neutral with regard to jurisdictional claims in published maps and institutional affiliations.

Ready to submit your research? Choose BMC and benefit from:

- fast, convenient online submission

- thorough peer review by experienced researchers in your field

- rapid publication on acceptance

- support for research data, including large and complex data types

- gold Open Access which fosters wider collaboration and increased citations

- maximum visibility for your research: over $100 \mathrm{M}$ website views per year

At BMC, research is always in progress.

Learn more biomedcentral.com/submissions 